\title{
Metabolic and Renal Effects of Dietary Advanced Glycation end Products in Pregnant Rats - A Pilot Study
}

\author{
K. JANŠÁKOVÁ ${ }^{1,2}$, E. LENGYELOVÁ ${ }^{1}$, N. PRIBULOVÁ ${ }^{1}$, V. SOMOZA ${ }^{3}$, P. CELEC $^{1,4,5}$, \\ K. ŠEBEKOVÁ ${ }^{1}$, D. OSTATNÍKOVÁ ${ }^{2}$, L. TÓTHOVÁ \\ ${ }^{1}$ Institute of Molecular Biomedicine, Faculty of Medicine, Comenius University, Bratislava, \\ Slovakia, ${ }^{2}$ Institute of Physiology, Faculty of Medicine, Comenius University, Bratislava, Slovakia, \\ ${ }^{3}$ Department of Nutritional and Physiological Chemistry, Faculty of Chemistry, University of \\ Vienna, Vienna, Austria, ${ }^{4}$ Institute of Pathological Physiology, Faculty of Medicine, Comenius \\ University, Bratislava, Slovakia, ${ }^{5}$ Department of Molecular Biology, Faculty of Natural Sciences, \\ Comenius University, Bratislava, Slovakia
}

Received December 10, 2018

Accepted January 29, 2018

Epub Ahead of Print March 22, 2019

\section{Summary}

Thermally processed food contains advanced glycation end products (AGEs) including $\mathrm{N}^{\varepsilon}$-(carboxymethyl)lysine (CML). Higher AGEs or circulating CML were shown to be associated with pregnancy complications such as preeclampsia and gestational diabetes. It is unclear whether this association is causal. The aim of our study was to analyze the effects of dietary CML and CML-containing thermally processed food on metabolism in pregnant rats. Animals were fed with standard or with AGE-rich diet from gestation day 1 . Third group received standard diet and CML via gavage. On gestation day 18, blood pressure was measured, urine and blood were collected and the oral glucose tolerance test was performed. Plasma AGEs were slightly higher in pregnant rats fed with the AGE-rich diet $(p=0.09)$. A non-significant trend towards higher $\mathrm{CML}$ in plasma was found in the CML group $(p=0.06)$. No significant differences between groups were revealed in glucose metabolism or markers of renal functions like proteinuria and creatinine clearance. In conclusion, this study does not support the hypothesis that dietary AGEs such as CML might induce harmful metabolic changes or contribute to the pathogenesis of pregnancy complications. The short duration of the rodent gestation warrants further studies analyzing long-term effects of $\mathrm{AGES} / \mathrm{CML}$ in preconception nutrition.
\end{abstract}

\section{Key words}

Glycotoxins • Melanoidins • Maillard reaction products • Metabolic syndrome $\bullet$ Insulin sensitivity

\section{Corresponding author}

L'. Tóthová, Institute of Molecular Biomedicine, Faculty of Medicine Comenius University, Sasinkova 4, 81108 Bratislava, Slovakia. E-mail: tothova.lubomira@gmail.com

\section{Introduction}

Advanced glycation end products (AGEs) are formed when sugars and other aldehydes interact with proteins in the so-called Maillard reaction. AGEs are involved in several physiological processes like bone metabolism, lung homeostasis or activation of immune response (e.g. via activation of $\mathrm{NF}-\kappa \mathrm{B}$ signaling pathway) (Ott et al. 2014). Nevertheless, the main causes of in vivo AGEs formation are hyperglycemia (Goldin et al. 2006), oxidative stress (Tan et al. 2007) and aging (Brownlee 1995). Circulating AGEs levels are especially high in diabetic patients (Nowotny et al. 2015). Formation and recognition of AGEs by the immune system are involved in the pathogenesis of chronic complications of diabetes mellitus (Goh and Cooper 2008, Yan et al. 2008), chronic renal insufficiency or even neurodevelopmental disorders such as those on the autism spectrum (Anwar et al. 2018). 
Besides formation in vivo, AGEs are also generated during thermal processing of food, especially frying and broiling (Goldberg et al. 2004). The concentration of AGEs depends on the temperature, duration of thermal processing, used ingredients and type of food. Dietary AGEs are found in a wide range of processed food, but they are present also in raw foods of animal or plant origin. Thus, the amount of ingested AGEs depends on individual dietary habits, but the consumption of thermally processed foods leads to a continuous exposure to AGEs (Sebekova and Brouder Sebekova). These diet-derived AGEs have been hypothesized to induce insulin resistance and diabetes (Vlassara and Uribarri 2014), and might contribute to the development of diabetes-associated inflammation and angiopathy (Vlassara et al. 2002). Moreover, it has been hypothesized that AGEs-rich diet might assist in the development of the autistic traits, thus, maternal lifestyle and dietary habits might play an important role in neurodevelopment (Maher 2012, Currais et al. 2016). However, whether AGEs are involved in the manifestation of diabetes and other disorders or whether an impaired glucose metabolism contributes to elevated AGE concentrations can only be tested in animal experiments.

Animal experiments have shown that chronic intake of dietary AGEs induces insulin resistance (Cai et al. 2012), accelerates the progress of renal fibrosis (Feng et al. 2007), liver inflammation (Patel et al. 2012), might cause oxidative status impairment (Firmin et al. 2018) and even loss of spatial memory in a model of neurodegeneration (Lubitz et al. 2016). More importantly, an interventional study in humans has shown that a reduction of AGEs intake improves insulin sensitivity, indicating potential preventive/therapeutic efficiency (Uribarri et al. 2011).

AGEs represent a heterogeneous group of compounds including, $\mathrm{N}^{\varepsilon}$-(carboxymethylhydroxy)lysine, $\mathrm{N}^{\varepsilon}$-(carboxyethyl)lysine and many others (Gkogkolou and Bohm 2012). $\mathrm{N}^{\varepsilon}$-(carboxymethyl)lysine (CML) is one of the first defined and most prevalent AGE compound (Ahmed et al. 1986, Delgado-Andrade 2016). CML can be found in high amounts in various foods belonging to the so called Western style diet (Hull et al. 2012). Bread, and especially the bread crust, are a major source of food-derived AGEs, with CML being most abundant (Helou et al. 2016). Chronic exposure to CML leads to its accumulation in various organs, especially those containing long-lived proteins, such as collagen (Roncero-Ramos et al. 2014, Tessier et al. 2016).
The most common complications of pregnancy are preeclampsia and gestational diabetes, and in both pathologies the association with AGEs has been investigated (Chekir et al. 2006, Harsem et al. 2008). Recently, plasma CML was found to be twice as high in pregnant women with gestational diabetes as in controls (Bartakova et al. 2016). Interestingly, complications of modeled gestational diabetes were absent in mice without the gene encoding the receptor for AGEs, suggesting that the activation by its ligands might be a part of the etiology of gestational diabetes (Ejdesjo et al. 2016). Similar findings have been reported in women with preeclampsia (Alexander et al. 2016). Plasma AGEs were found to be higher in comparison to healthy controls already in the first two trimesters and were associated with inflammatory markers (Yu et al. 2012). However, whether dietary AGEs are involved in the pathogenesis of common pregnancyrelated complications remains unknown.

The aim of our study was to analyze the metabolic and renal effects of dietary CML administered via oral gavage and CML-containing AGE-rich food. AGE-rich food was provided in form of bread crusts in an interventional experiment in pregnant rats throughout gestation due to its relation with pregnancy complications like gestational diabetes and preeclampsia.

\section{Materials and Methods}

The experiment was performed in compliance with EU Guidelines for scientific experimentation on animals Directive 2010/63/EU, and with the approval of the Institutional ethical committee of the Institute of Normal and Pathological Physiology, Faculty of Medicine, Comenius University in Bratislava, Slovakia.

\section{Design of the experiment}

Twenty-eight female Wistar rats (Anlab, Prague, Czech Republic) were mated after reaching the reproductive age with their male counterparts. However, only 18 of them got and remained pregnant. The presence of sperms in vaginal smears was used to check for successful mating and considered as the first day of pregnancy. Pregnant rats were randomized into 3 groups: control group (CTRL, $\mathrm{n}=7$ ), advanced glycation end products group (AGEs, $\mathrm{n}=5$ ) and $\mathrm{N}^{\varepsilon}$-(carboxymethyl)lysine group $(C M L, n=6)$. Rats in the CTRL group had ad libitum access to standard pelleted diet (KKZ-P-M, Top Dovo, Dobrá Voda, Slovakia, Table 1) throughout the experiment. Animals in the AGEs and CML groups 
were pair-fed according to the food consumption in the CTRL group. The AGEs group received an AGE-rich diet consisting of $75 \% \mathrm{wt} / \mathrm{wt}$ of the control diet (Table 1) and $25 \% \mathrm{wt} / \mathrm{wt}$ bread crusts as thermally processed food as described previously (Šebeková et al. 2003). The energy content was $290 \mathrm{kcal} / 100 \mathrm{~g}$ and $390 \mathrm{kcal} / 100 \mathrm{~g}$ for control and AGE-rich diet, respectively (Faist et al. 2002, Sebekova et al. 2012).

Table 1. Composition of the control feeding diet.

\begin{tabular}{lc}
\hline Ingredients & Proportion \\
\hline Wheat & $50 \%$ \\
Meat and bone meal & $11 \%$ \\
Oats & $8 \%$ \\
Barley & $8 \%$ \\
Alfalfa & $6 \%$ \\
Extruded soybeans & $6 \%$ \\
Wheat bran & $4 \%$ \\
Wheat sprouts & $4 \%$ \\
Mineral additives & $1.4 \%$ \\
Sunflower oil & $1 \%$ \\
Vitamin premix & $0.6 \%$ \\
\hline
\end{tabular}

Rats in the CML group received the standard diet, but were also orally gavaged with CML on a daily basis throughout the gestation. The dose of gavaged CML was calculated according to the amount of food consumed by the animals in the AGEs group (one gram of bread crusts corresponding to $0.65 \mathrm{mg}$ of CML) (Faist et al. 2002). Rats were kept separately in plastic cages on a 12/12 h light/dark cycle in a temperature and humidity controlled room. All groups had free access to tap water during the whole experiment.

Body weight and food consumption were monitored daily. On gestation day 18, blood pressure was measured using the non-invasive tail cuff method (ADInstruments, Spechbach, Germany) in the morning. Thereafter, fasting blood samples (6 h fasting) were collected from the tail vein into Microvette EDTA tubes (Sarstedt, Numbrecht, Germany). Thereafter, all rats were placed into metabolic cages for $24 \mathrm{~h}$ for stool-free urine collection.

The samples were centrifuged immediately at $2,000 \times \mathrm{g}$ for $10 \mathrm{~min}$ and plasma was frozen at $-80{ }^{\circ} \mathrm{C}$ for further analyses. Thereafter, an oral glucose tolerance test was performed. Gestation length and the litter size were recorded at the end of the experiment. Whole experiment is described in Figure 1.

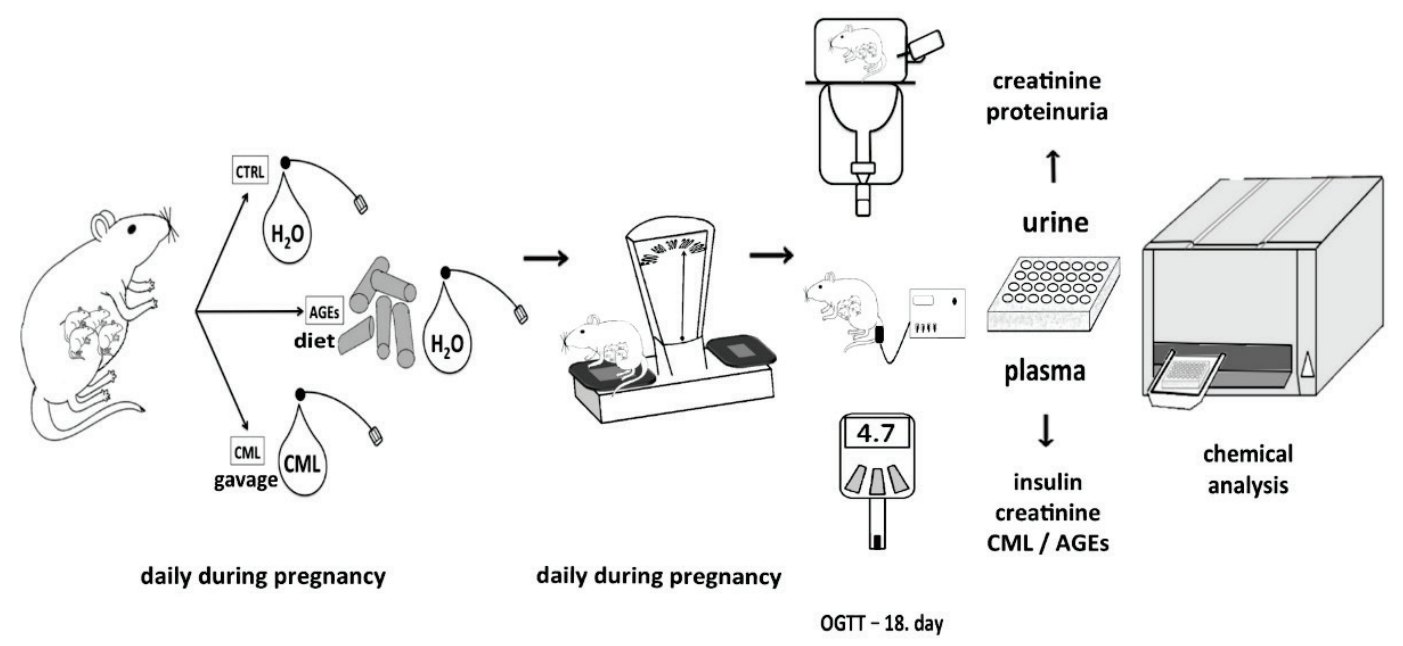

Fig. 1. Design of the experiment.

\section{Insulin sensitivity}

Insulin was measured in fasting plasma using a mammalian insulin ELISA kit (Mercodia AB, Uppsala, Sweden), according to the instructions of the manufacturer. For the oral glucose tolerance test, glucose ( $2 \mathrm{~g} / \mathrm{kg}$ of body weight). was dissolved in tap water $(500 \mu \mathrm{l})$ and administered orally by gastric gavage. Blood glucose was measured immediately before glucose administration and again at 15, 30, 60 and 120 min using a standard glucometer (Accu-Chek Performa, Roche, Basel, Switzerland). Glucose dynamics was evaluated using calculations of positive incremental and total area under the curve (AUC). In addition, the homeostatic model assessment of insulin resistance (HOMA-IR) was 
calculated from fasting glucose and insulin concentrations (Matthews et al. 1985).

\section{Renal function tests}

The volume of urine collected in the metabolic cages was recorded. The concentration of urinary creatinine was assessed using the spectrophotometric method described by Jaffe (1886). The concentration of plasma creatinine was assessed using the commercially available Creatinine detection kit (Arbor Assays, Ann Arbor, Michigan, USA). Creatinine clearance was calculated. Proteinuria was analyzed using the pyrogallol red method (Watanabe et al. 1986), as described previously.

\section{AGEs and CML analysis}

AGE-associated fluorescence of plasma and both, control and AGEs-rich diet (10\% homogenates) was determined fluorimetrically $\left(\lambda_{\mathrm{ex}}=370 \mathrm{~nm} / \lambda_{\mathrm{em}}=440 \mathrm{~nm}\right)$, using a previously described method (Munch et al. 1997). For quantitative analysis, an external calibration using AGE-modified bovine serum albumin was used. The concentration of CML in plasma was analyzed using the AGE - CML ELISA kit (Microcoat, Bernried am Starnberger See, Germany), according to the instructions of the manufacturer. The concentration of total proteins was measured using the bicinchoninic acid method (Sigma-Aldrich, Munich, Germany). Bovine serum albumin was used as reference for external calibration. All measurements were performed on a Tecan Sapphire II microplate reader (Grödig, Austria). Concentration of CML in AGEs-rich diet was analyzed by reverse-phase high performance liquid chromatography, as described previously (Faist et al. 2002).

\section{Statistical analysis}

Power analysis was performed using G Power
3.1.9.2 (Universität Kiel, Germany). To achieve statistical power of 0.80 , AGEs and CML were used as end-point variables. Preliminary data suggested an expected effect size of $\mathrm{f}=0.61$ and $\mathrm{f}=0.56$, respectively. The number of animals for 3 groups was calculated to be 21 and 24, respectively (F test, ANOVA: repeated measures, between factors). However, only 18 female animals got and remain pregnant in the experiment, i.e. the final achieved power was 0.72 for AGEs and 0.64 for CML.

The data were further analyzed using GraphPad Prism 7.01 (La Jolla, California, USA). One-way ANOVA, and repeated measures ANOVA were used for the comparison of groups and for time series analysis, respectively. Bonferroni-modified t-test was used as a post hoc test to partially prevent multiple comparison bias. Statistical significance was set to $p<0.05$. All data are presented as mean \pm standard deviation. Mischief (Made with Mischief Inc., The Foundry, London, UK) and Microsoft Office PowerPoint 2011 (Microsoft Corporation, Redmond, USA) were used for creation of artwork.

\section{Results}

Body weight of pregnant rats increased continuously during gestation $(\mathrm{F}=40.2, \mathrm{p}<0.001)$. No differences were found between the groups throughout the experiment $(\mathrm{F}=0.24, \mathrm{p}>0.99$, Fig. 2). Analyses of renal functions revealed differences between the groups neither for plasma creatinine $(\mathrm{F}=0.72, \mathrm{p}=0.50$, Fig. 3a) nor for creatinine clearance $(F=1.98, p=0.17$, Fig. $3 b)$. Similarly, no differences were observed between the groups in proteinuria $(\mathrm{F}=0.30, \mathrm{p}=0.75$, Fig. $3 \mathrm{c})$. Analysis of urine revealed high inter-individual variability in all groups. Neither AGE-rich diet nor CML administration affected systolic blood pressure $(\mathrm{F}=0.58, \mathrm{p}=0.57$, Fig. 4).

\section{Body weight during gestation}

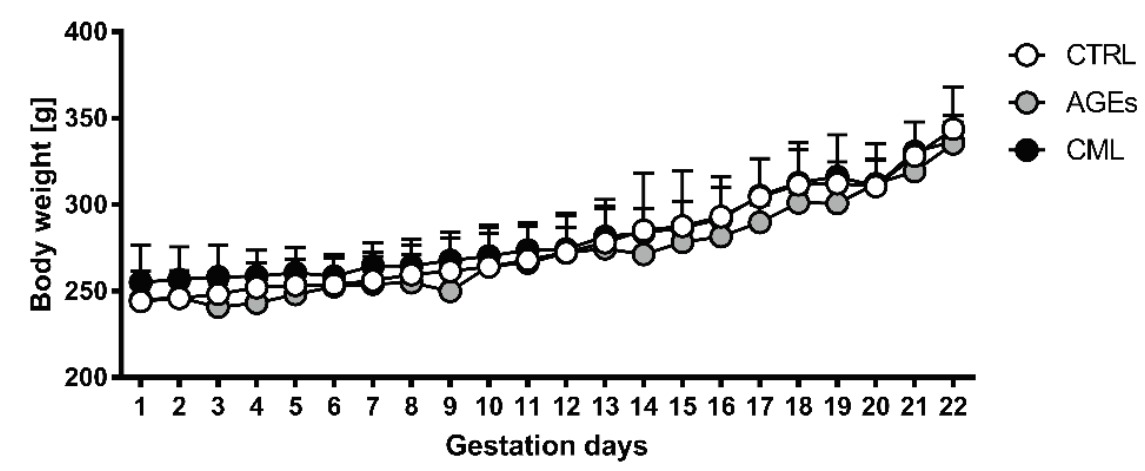

Fig. 2. Body weight dynamics. The weight of the pregnant rats was monitored daily throughout the whole gestation. Data are presented as the mean + SD. 
(a) Plasma creatinine

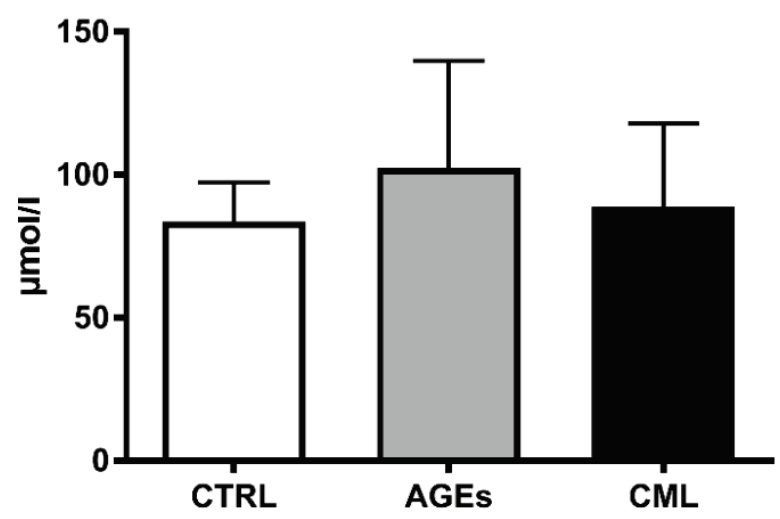

(b)

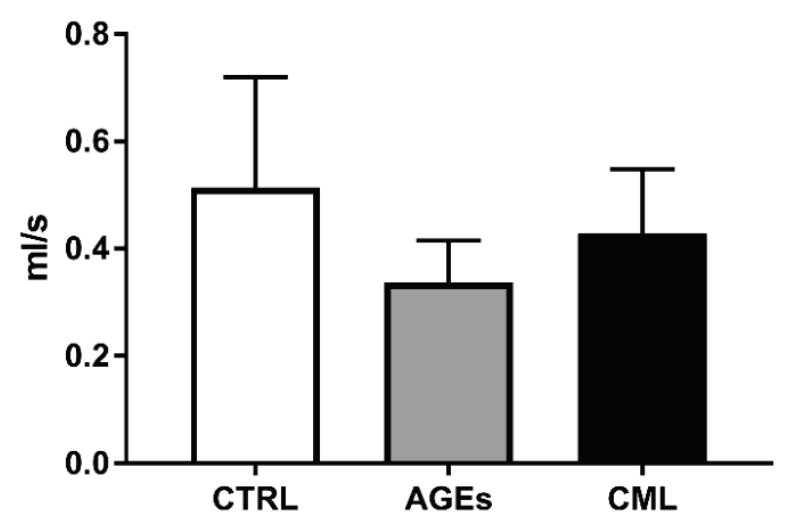

(c)

Proteinuria

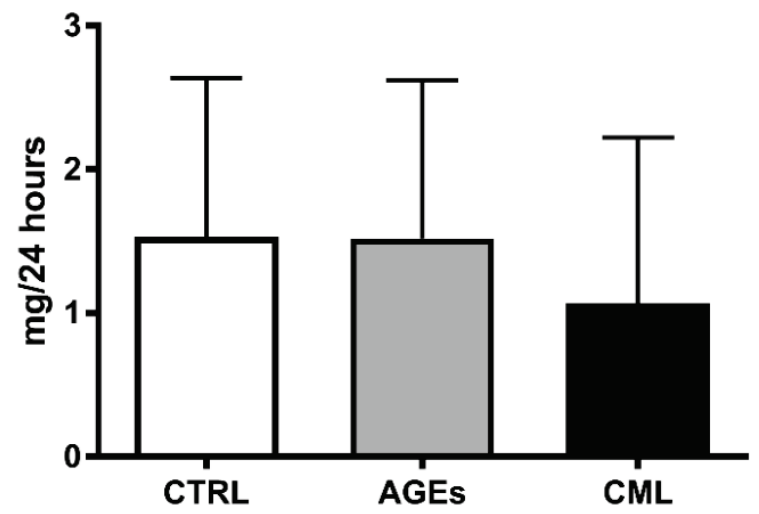

Fig. 3. Renal functions. Plasma creatinine (a), creatinine clearance (b) and proteinuria (c) were measured at the end gestation and did not differ between the groups. Data are presented as the mean + SD.

To assess glucose metabolism, fasting blood glucose and insulin were measured before glucose administration. Fasting glucose was $3.7 \pm 0.9 \mathrm{mmol} / \mathrm{l}$ in the CTRL group. Although the average concentrations in experimental groups were slightly higher $(4.3 \pm 0.5 \mathrm{mmol} / 1$ in the AGEs group, and $4.1 \pm 1.2 \mathrm{mmol} / 1$ in the CML group), the differences in comparison to the CTRL group were not significant $(\mathrm{F}=0.71, \mathrm{p}=0.51$, Fig. 5a). Mean fasting insulin concentrations were $0.48 \pm 0.35 \mu \mathrm{g} / 1$ in the AGEs group, $0.37 \pm 0.08 \mu \mathrm{g} / 1$ in the CML group and $0.54 \pm 0.38 \mu \mathrm{g} / 1$ in the CTRL group. These differences did not reach the level of statistical significance $(\mathrm{F}=0.52$, $\mathrm{p}=0.60$, Fig. $5 \mathrm{~b}$ ). The calculated HOMA-IR was also similar between the groups $(F=0.53, p=0.60$, Fig. $5 c)$. These results did not statistically differ between groups probably due to already above-mentioned inter-individual variability and inability to meet the requirements for statistical power.

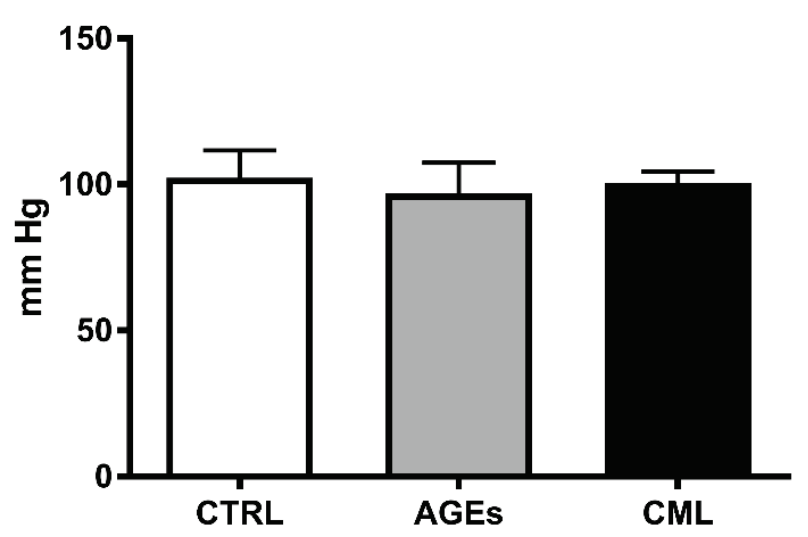

Fig. 4. Systolic blood pressure. Non-invasive tail-cuff method was used for the single blood pressure measurement assessed on the $18^{\text {th }}$ day of the gestation. No differences between the groups were found. Data are presented as the mean + SD.

In the oral glucose tolerance test, the highest values of blood glucose were found $15 \mathrm{~min}$ after glucose administration and gradually declined in all three groups. The dynamics of blood glucose during the oral glucose tolerance test was significant $(\mathrm{F}=29.4, \mathrm{p}<0.001)$, but no differences between groups were observed $(\mathrm{F}=0.14$, $\mathrm{p}=0.87$, Fig. 6a). Total AUC $(\mathrm{F}=0.17, \mathrm{p}=0.84$, Fig. $6 \mathrm{~b})$, and positive incremental AUC $(\mathrm{F}=0.60, \mathrm{p}=0.56$, Fig. 6c) calculations confirmed the lack of significant differences between the groups in insulin sensitivity.

Measurement of AGE-associated fluorescence in the consumed food types revealed 9.6-times higher values in AGEs-rich diet (61-367 arbitrary units - AU) compared to control standard diet $(6,421$ AU) $(t=30.97$, $\mathrm{p}<0.001)$. The average AGE-associated fluorescence of plasma samples was $21 \%$ higher in the AGEs group, and $30 \%$ higher in the CML group in comparison to control animals. The differences were not significant $(\mathrm{F}=2.80$, $\mathrm{p}=0.09$, Fig. 7a). Assessment of plasma CML concentrations showed a trend towards higher values in 
the AGE (by $28 \%$ ) and CML (by $57 \%$ ) groups compared to the CTRL group $(p=0.06)$. The difference between the groups was found to be marginally non-significant $(\mathrm{F}=2.93, \mathrm{p}=0.08$, Fig. $7 \mathrm{~b})$.

(a)

\section{Fasting glucose}

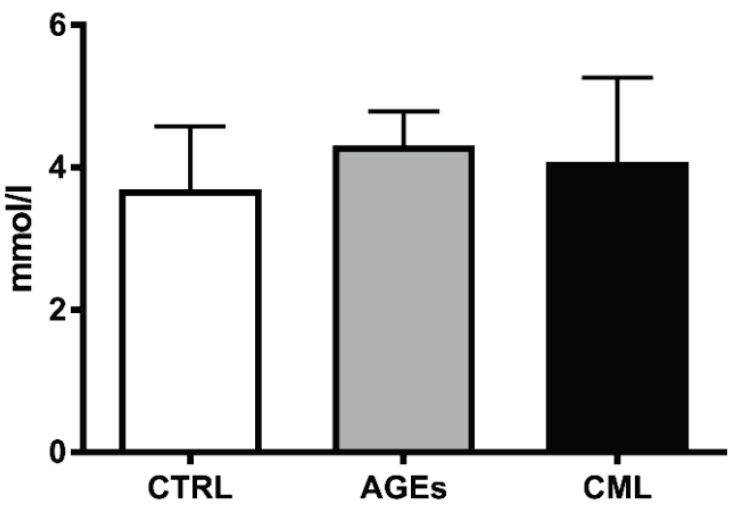

(b)

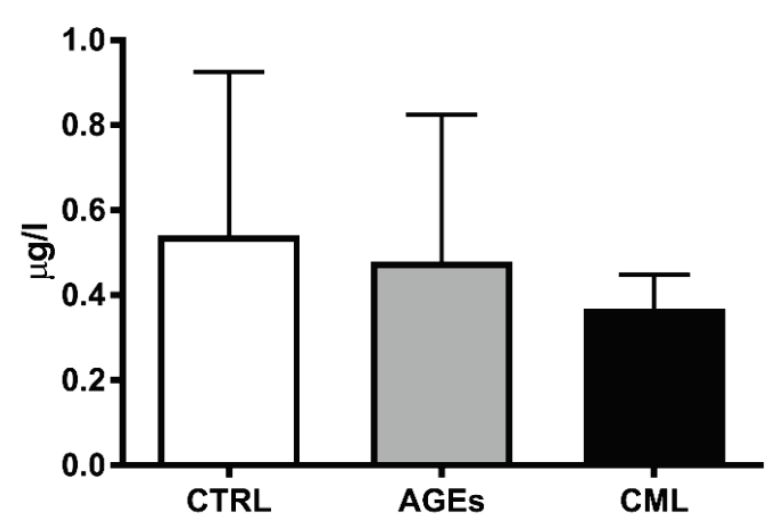

(c)

\section{Insulin resistance}

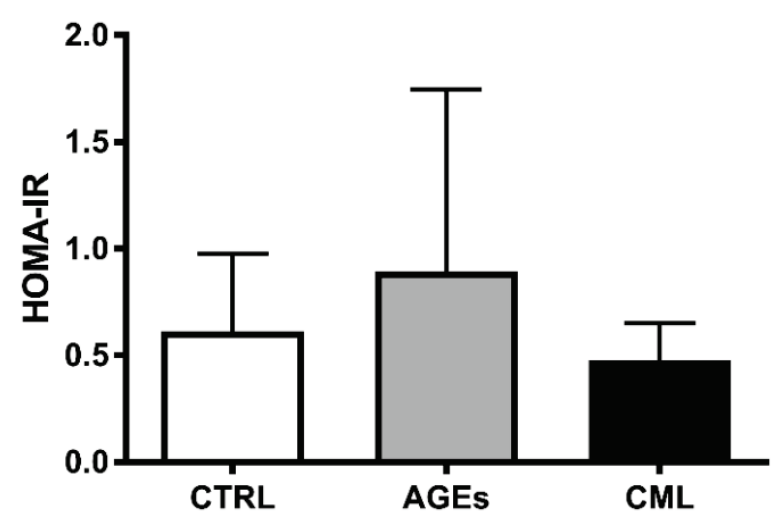

Fig. 5. Insulin sensitivity. In fasting blood samples the concentrations of glucose were assessed (a). Fasting insulin was measured using ELISA in plasma samples (b). The homeostatic model assessment of insulin resistance (HOMA-IR) was calculated (c). No differences in insulin sensitivity were found between the groups. Data are presented as the mean + SD.
The observed gestational length and the litter size at delivery were similar between the groups $(\mathrm{F}=0.75$, $\mathrm{p}=0.49$ and $\mathrm{F}=1.23, \mathrm{p}=0.31$, respectively; Fig. 8 ). The number of delivered pups was $10 \pm 2.7$ in the CTRL group, $11 \pm 1.8$ for the AGEs group and $9 \pm 2.4$ for the CML group.

(a)

Oral glucose tolerance test

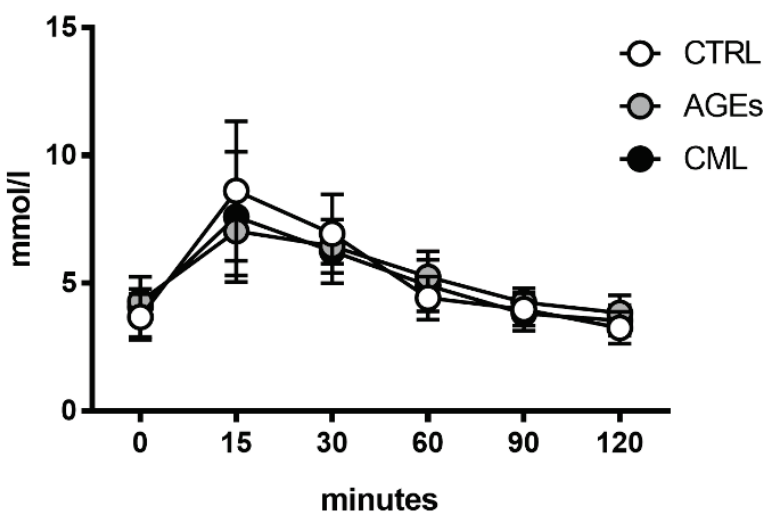

(b)

Total AUC

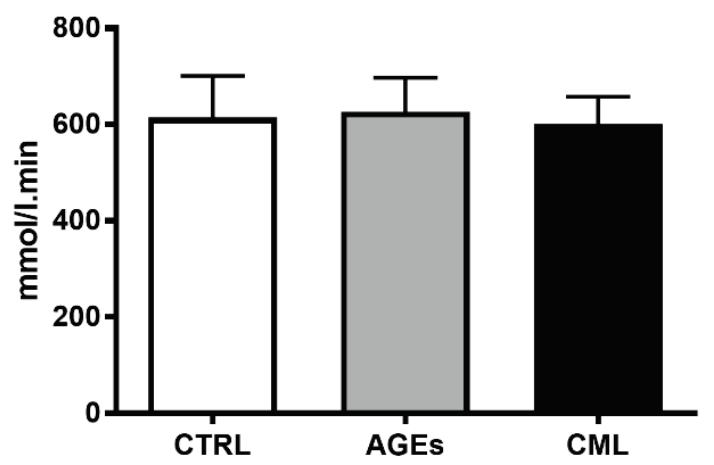

(c) Positive incremental AUC

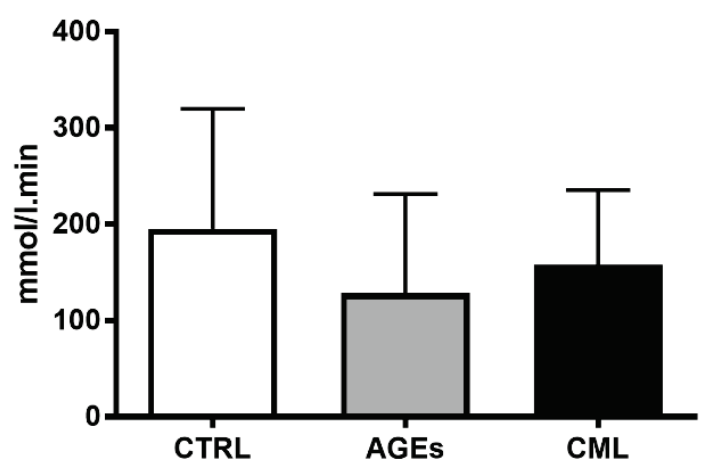

Fig. 6. Oral glucose tolerance test. The dynamics of blood glucose concentrations was observed before and after glucose administration via oral gavage (a). Based on the glucose dynamics, total (b) and positive incremental (c) areas under curve were calculated. Data are presented as the mean + SD. 
(a)

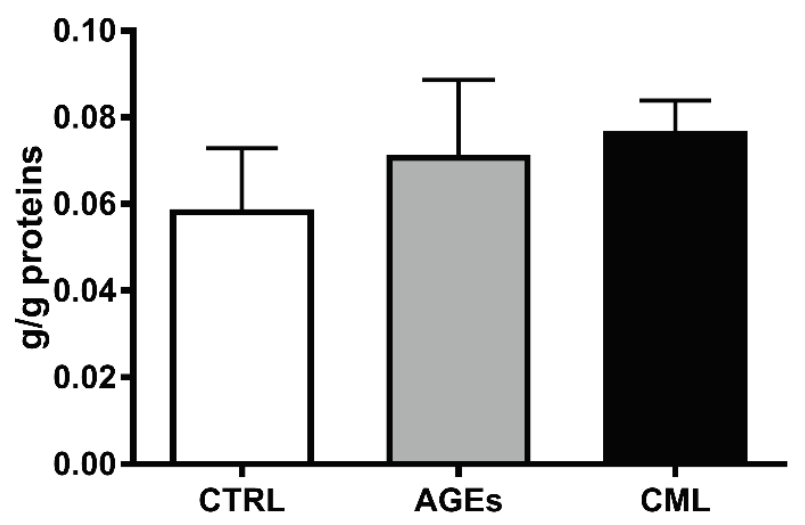

(b)

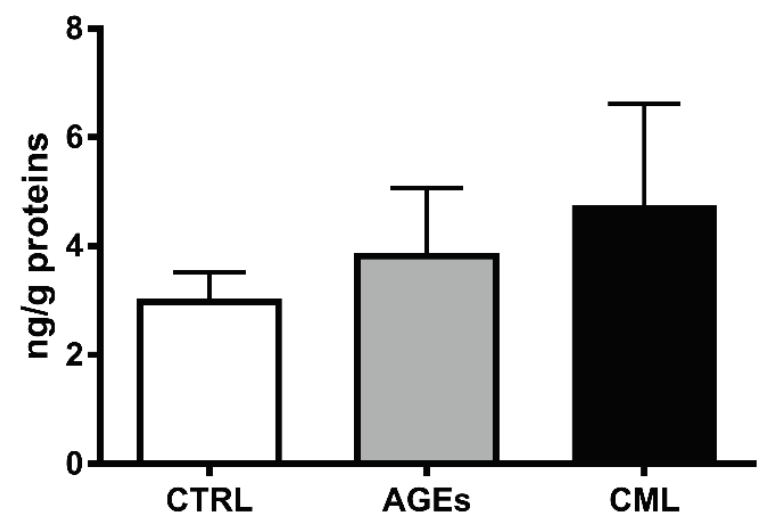

Fig. 7. In collected plasma samples, advanced glycation end products (AGEs) were assessed using AGE-specific fluorescence (a). ELISA kit was used for the measurement of $\mathrm{N}^{\varepsilon}$-(carboxymethyl)lysine (CML, b). Concentrations were normalized to total plasma proteins. No significant differences between groups were found. Data are presented as the mean + SD.

\section{Discussion}

AGEs can be found in high amounts in numerous commonly consumed foods (Goldberg et al. 2004). Dietary AGEs seem to worsen or even induce complications of several chronic diseases (LuevanoContreras and Chapman-Novakofski 2010). As AGEs are linked to gestational diabetes (Pertynska-Marczewska et al. 2009) and preeclampsia (Coffeng et al. 2011, Chen et al. 2017), it is reasonable to assume that dietary AGEs might also contribute to the etiopathogenesis of these most common pregnancy-related complications. In our controlled feeding experiment, high AGEs/CML intake throughout gestation did not affect metabolic outcome measures in pregnant rats. Neither renal functions nor insulin sensitivity were affected. Weight gain during (a)

Gestation length

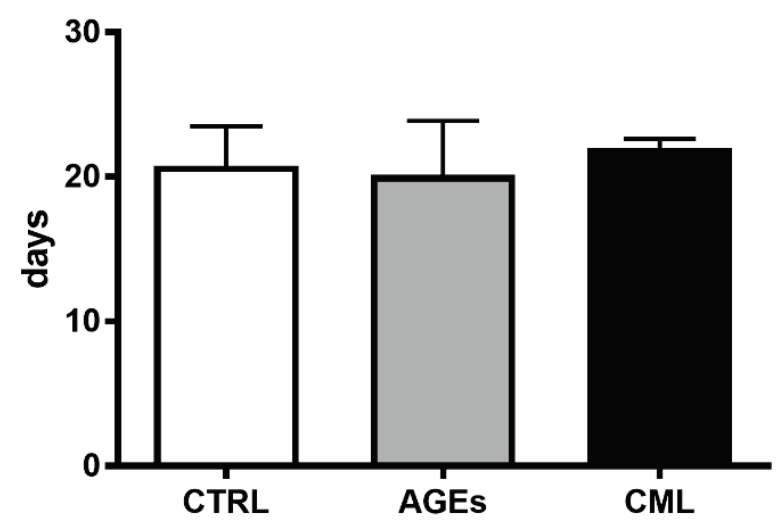

(b)

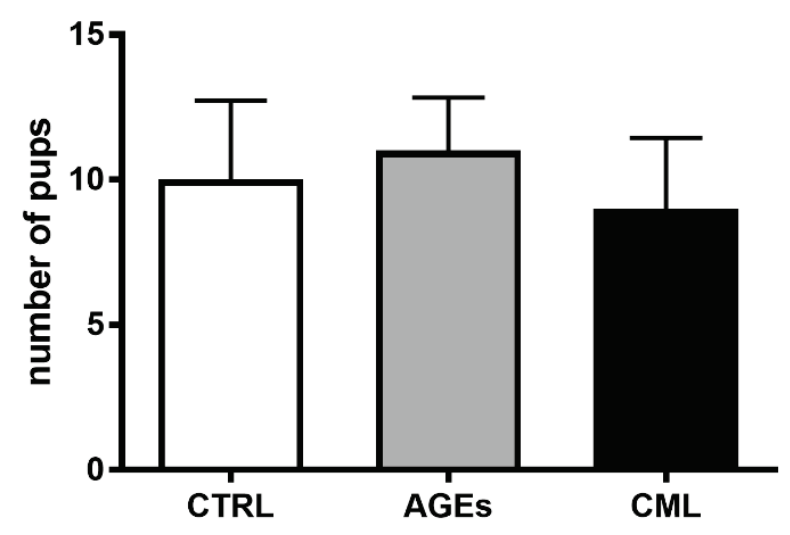

Fig. 8. Gestation length and litter size. The day of delivery and, thus, the gestation length was monitored (a). In addition, the number of pups was recorded for each rat as litter size (b). No differences between the groups were found. Data are presented as the mean $+\mathrm{SD}$.

gestation, and litter size were also not different between control and experimental groups.

The lack of significant differences in plasma AGEs and CML do not affect the relevance of the other results since the foods differed significantly in their AGEs content. The daily dose of consumed AGEs and gavaged CML was similar or even higher in comparison with other animal studies (Alamir et al. 2013, RonceroRamos et al. 2013, Poulsen et al. 2016) and much higher than the amount of AGEs in commonly consumed meals used in human studies (Birlouez-Aragon et al. 2010). Inconsistent outcomes of AGE feeding studies can be explained by varying digestive and microbial degradation of dietary AGEs in the gut, their poor absorption, and renal excretion of the absorbed AGEs (Forster et al. 2005). In other studies, the excreted CML was found in 
the urine and feces (Roncero-Ramos et al. 2013). The concentration of excreted CML in stool correlated with the amount of ingested CML. Absorbed CML was found in the heart and tail tendon. Unfortunately, such analyses have not been performed in our study. However, similarly to our study, protein bound CML as well as free CML in plasma was not elevated in the groups with AGEs-rich diet when compared to low AGEs diet (Alamir et al. 2013, Roncero-Ramos et al. 2013).

While some studies clearly show negative health effects even after a bolus administration (Koschinsky et al. 1997), other human studies have found no effects of 6 weeks-long high intake of AGEs (Semba et al. 2014). Practical guidelines to reduce the intake of AGEs are already published (Uribarri et al. 2010). However, a systematic review reported that there is insufficient evidence for recommending an AGE-restricted diet (Kellow and Savige 2013). In the recent study, even an increase of insulin sensitivity has been observed in mice fed a CML-containing Western diet for 8 weeks (Ward et al. 2016). Clearly, more research is needed in this area.

A major limitation of our experiment is the low number of animals in individual groups. Next, the duration of rodent pregnancy is much shorter than in humans. Also, rats used in this study were mating shortly after reaching the adulthood, thus, they were quite young to manifest profound age-related AGE-modification of proteins. Considering the duration of pregnancy, in interventional studies, pregnant women would be exposed to an AGEs-rich diet much longer when compared to rodents. However, it would be difficult to perform a similar clinical study. In general, human diet is more complex, thus, it would not be possible to ensure analogous diet necessary for this type of study for such a long time period, especially during pregnancy. On the other hand, observational studies comparing women consuming high- vs. low-AGEs diets would be biased by additional nutritional, metabolic, and other differences between the groups.

Nevertheless, studies regarding diet performed on rodents have already been published (Ruhlen et al. 2011, Zhang et al. 2013). Our results are in line with a recently published study in non-pregnant rats, showing no metabolic consequences of short-term dietary AGE intake (Poulsen et al. 2016). The lack of significant differences in plasma AGEs or CML between the groups in our study could be explained by their low and fast absorption from food, rapid excretion by kidneys
(Gugliucci and Bendayan 1996, Koschinsky et al. 1997), their accumulation in the tissues (Tessier et al. 2016) or by low number of animals and high variability. Also, it is likely that AGEs accumulated in the tissues rather than in plasma.

Lastly, we measured total and not proteinbounded CML as recommended by others (RonceroRamos et al. 2013). In pregnant women, even a single oral glucose load has been shown to increase plasma CML (Williams et al. 2012). Whereas we did not observe differences in fasting glucose or glucose dynamics during the oral glucose tolerance test, variability of blood glucose was not assessed during the whole gestation period. However, experimental studies performed on rats showed that concentration of glucose, glycated hemoglobin and fructosamine decrease by the end of gestation (Preston et al. 1992).

This might introduce bias contributing to the lack of significant differences in plasma AGEs/CML despite clearly higher intake of AGEs/CML. Nevertheless, these technical limitations do not affect the major negative findings of our experiment. Especially, while the daily dose of CML in our experiment was similar to that administered in other animal experiments (Li et al. 2015), and substantially higher than dietary AGEs-load in clinical studies focusing on the effects of AGE-rich diets (Poulsen et al. 2014). Our former studies showed that prenatal oral challenge with dietary AGEs exert postnatal effects in offspring, but these studies focused on the offspring rather than the pregnant dams (Gurecka et al. 2015, Csongova et al. 2018).

There is another study confirming the harmful effect of dietary AGEs performed by Cai et al. (2012) on mice. They showed that consumption of AGEs in form of diet enriched with AGEs precursor methylglyoxal throughout the life had negative consequences on the following generations proven by the lower insulin sensitivity, higher leptin level, lower adiponectin and higher plasma/white fat CML and methylglyoxal concentrations. Interestingly, they observed no effect of the AGEs-rich diet on the body weight gain. Moreover, higher body weight was observed in mice fed with standard diet without AGEs.

Results observed by Cai et al. (2012) point to the consequences of epigenetics and overall eating habits on the offspring. On the other hand, AGEs-rich diet used in this study was not prepared naturally by exposure to high-temperature but by adding of a synthetically prepared methylglyoxal. The effect of ingested reactive 
AGE-precursor might differ from that of dietary (naturally formed) AGEs.

According to our knowledge, this is the first experiment studying the metabolic and renal effects of dietary AGEs in pregnant animals. Despite negative findings and several limitations, our results are of importance, since this experiment is the first to test whether high intake of AGEs/CML induces features of gestational diabetes or preeclampsia. One of the potential explanation of the lack of observed metabolic or renal effects might be that the animals were on a standard diet, while high-fat diet has been shown to increase CML absorption (Davis et al. 2015). Based on previously published research, we hypothesized that AGEs might induce embryonal toxicity (Hao et al. 2008). In addition, another study showed that preexisting maternal diabetes leads to accumulation of AGEs, including CML accumulation in the blastocyst (Haucke et al. 2014). However, as neither the weight gain during pregnancy, nor the litter size were affected by dietary AGEs/CML, the results presented here do not support our hypothesis. On the other hand, if the treatment with dietary AGEs would have started earlier, i.e. before conception, our results might have been different.

In conclusion, our experiment does not support the hypothesis that high dietary intake of AGEs/CML, if limited to the period of pregnancy, induces or participates on the pathogenesis of pregnancy-related complications including gestational diabetes, hypertension or preeclampsia. More likely, the observed higher AGEs/CML in pathological pregnancies might rather be a consequence than a cause of the disease pathomechanisms (Bartakova et al. 2016). Taking into account the short duration of our experiment and the healthy status of pregnant rats, our results do not exclude the possibility that high dietary AGEs/CML intake might induce negative effects in human pregnancies or in pregnant animals with already established insulin resistance, diabetes or kidney diseases. Further studies should focus on the effects of long-term intake of dietary AGEs/CML, especially during the preconception period.

\section{Conflict of Interest}

There is no conflict of interest.

\section{Acknowledgements}

This study was supported by grant from Ministry of Education, Science, Research and Sport of the Slovak Republic (VEGA 1/0062/2016) and by the Slovak Research and Development Agency grant number (APVV 15-0045).

\section{References}

AHMED MU, THORPE SR, BAYNES JW: Identification of N epsilon-carboxymethyllysine as a degradation product of fructoselysine in glycated protein. J Biol Chem 261: 4889-4894, 1986.

ALAMIR I, NIQUET-LERIDON C, JACOLOT P, RODRIGUEZ C, OROSCO M, ANTON PM, TESSIER FJ: Digestibility of extruded proteins and metabolic transit of $N^{\varepsilon}$-carboxymethyllysine in rats. Amino Acids 44: 1441-1449, 2013.

ALEXANDER KL, MEJIA CA, JORDAN C, NELSON MB, HOWELL BM, JONES CM, REYNOLDS PR, ARROYO JA: Differential receptor for advanced glycation end products expression in preeclamptic, intrauterine growth restricted, and gestational diabetic placentas. Am J Reprod Immunol 75: 172-180, 2016.

ANWAR A, ABRUZZO PM, PASHA S, RAJPOOT K, BOLOTTA A, GHEZZO A, MARINI M, POSAR A, VISCONTI P, THORNALLEY PJ, RABBANI N: Advanced glycation endproducts, dityrosine and arginine transporter dysfunction in autism - a source of biomarkers for clinical diagnosis. Mol Autism 9: 3, 2018.

BARTAKOVA V, KOLLAROVA R, KURICOVA K, SEBEKOVA K, BELOBRADKOVA J, KANKOVA K: Serum carboxymethyl-lysine, a dominant advanced glycation end product, is increased in women with gestational diabetes mellitus. Biomed Pap Med Fac Univ Palacky Olomouc Czech Repub 160: 70-75, 2016.

BIRLOUEZ-ARAGON I, SAAVEDRA G, TESSIER FJ, GALINIER A, AIT-AMEUR L, LACOSTE F, NIAMBA CN, ALT N, SOMOZA V, LECERF JM: A diet based on high-heat-treated foods promotes risk factors for diabetes mellitus and cardiovascular diseases. Am J Clin Nutr 91: 1220-1226, 2010.

BROWNLEE M: Advanced protein glycosylation in diabetes and aging. Annu Rev Med 46: 223-234, 1995. 
CAI W, RAMDAS M, ZHU L, CHEN X, STRIKER GE, VLASSARA H: Oral advanced glycation endproducts (AGEs) promote insulin resistance and diabetes by depleting the antioxidant defenses AGE receptor-1 and sirtuin 1. Proc Natl Acad Sci U S A 109: 15888-15893, 2012.

CHEKIR C, NAKATSUKA M, NOGUCHI S, KONISHI H, KAMADA Y, SASAKI A, HAO L, HIRAMATSU Y: Accumulation of advanced glycation end products in women with preeclampsia: possible involvement of placental oxidative and nitrative stress. Placenta 27: 225-233, 2006.

CHEN W, ZHANG Y, YUE C, YE Y, CHEN P, PENG W, WANG Y: Accumulation of advanced glycation end products involved in inflammation and contributing to severe preeclampsia, in maternal blood, umbilical blood and placental tissues. Gynecol Obstet Invest 82: 388-397, 2017.

COFFENG SM, BLAAUW J, SOUWER ET, RAKHORST G, SMIT AJ, GRAAFF R, VAN DOORMAAL JJ, AARNOUDSE JG, FAAS MM, VAN PAMPUS MG: Skin autofluorescence as marker of tissue advanced glycation end-products accumulation in formerly preeclamptic women. Hypertens Pregnancy 30: 231-242, 2011.

CSONGOVA M, GURECKA R, KOBOROVA I, CELEC P, DOMONKOS E, ULICNA O, SOMOZA V, SEBEKOVA $\mathrm{K}$ : The effects of a maternal advanced glycation end product-rich diet on somatic features, reflex ontogeny and metabolic parameters of offspring mice. Food Funct 9: 3432-3446, 2018.

CURRAIS A, FARROKHI C, DARGUSCH R, GOUJON-SVRZIC M, MAHER P: Dietary glycemic index modulates the behavioral and biochemical abnormalities associated with autism spectrum disorder. Mol Psychiatry 21: 426-436, 2016.

DAVIS KE, PRASAD C, VIJAYAGOPAL P, JUMA S, ADAMS-HUET B, IMRHAN V: Contribution of dietary advanced glycation end products (AGE) to circulating AGE: role of dietary fat. Br J Nutr 114: 1797-1806, 2015.

DELGADO-ANDRADE C: Carboxymethyl-lysine: thirty years of investigation in the field of AGE formation. Food Funct 7: 46-57, 2016.

EJDESJO A, BRINGS S, FLEMING T, FRED RG, NAWROTH PP, ERIKSSON UJ: Receptor for advanced glycation end products (RAGE) knockout reduces fetal dysmorphogenesis in murine diabetic pregnancy. Reprod Toxicol 62: 62-70, 2016.

FAIST V, HOFMANN T, ZILL H, BAYNES JW, THORPE SR, SEBEKOVA K, SCHINZEL R, HEIDLAND A, WENZEL E, ERBERSDOBLER HF: Effects of dietary Ne-carboxymethyllysine on expression of the biotransformation enzyme, glutathione-S-transferase, in the rat. Int Congress Series 1245: 313-320, 2002.

FENG JX, HOU FF, LIANG M, WANG GB, ZHANG X, LI HY, XIE D, TIAN JW, LIU ZQ: Restricted intake of dietary advanced glycation end products retards renal progression in the remnant kidney model. Kidney Int 71: 901-911, 2007.

FIRMIN S, ELMHIRI G, CREPIN D, SOUIDI M, TAOUIS M, ABDENNEBI-NAJAR L: Formula derived Maillard reaction products in post-weaning intrauterine growth-restricted piglets induce developmental programming of hepatic oxidative stress independently of microRNA-21 and microRNA-155. J Dev Orig Health Dis 9: 566-572, 2018.

FORSTER A, KUHNE Y, HENLE T: Studies on absorption and elimination of dietary Maillard reaction products. Ann N Y Acad Sci 1043: 474-481, 2005.

GKOGKOLOU P, BOHM M: Advanced glycation end products: Key players in skin aging? Dermatoendocrinol 4: 259-270, 2012.

GOH SY, COOPER ME: Clinical review: The role of advanced glycation end products in progression and complications of diabetes. J Clin Endocrinol Metab 93: 1143-1152, 2008.

GOLDBERG T, CAI W, PEPPA M, DARDAINE V, BALIGA BS, URIBARRI J, VLASSARA H: Advanced glycoxidation end products in commonly consumed foods. J Am Diet Assoc 104: 1287-1291, 2004.

GOLDIN A, BECKMAN JA, SCHMIDT AM, CREAGER MA: Advanced glycation end products: sparking the development of diabetic vascular injury. Circulation 114: 597-605, 2006.

GUGLIUCCI A, BENDAYAN M: Renal fate of circulating advanced glycated end products (AGE): evidence for reabsorption and catabolism of AGE-peptides by renal proximal tubular cells. Diabetologia 39: 149-160, 1996. 
GURECKA R, KOBOROVA I, JANSAKOVA K, TABI T, SZOKO E, SOMOZA V, SEBEKOVA K, CELEC P: Prenatal dietary load of Maillard reaction products combined with postnatal Coca-Cola drinking affects metabolic status of female Wistar rats. Croat Med J 56: 94-103, 2015.

HAO L, NOGUCHI S, KAMADA Y, SASAKI A, MATSUDA M, SHIMIZU K, HIRAMATSU Y, NAKATSUKA M: Adverse effects of advanced glycation end products on embryonal development. Acta Med Okayama 62: 93-99, 2008.

HARSEM NK, BRAEKKE K, TORJUSSEN T, HANSSEN K, STAFF AC: Advanced glycation end products in pregnancies complicated with diabetes mellitus or preeclampsia. Hypertens Pregnancy 27: 374-386, 2008.

HAUCKE E, NAVARRETE SANTOS A, SIMM A, HENNING C, GLOMB MA, GURKE J, SCHINDLER M, FISCHER B, NAVARRETE SANTOS A: Accumulation of advanced glycation end products in the rabbit blastocyst under maternal diabetes. Reproduction 148: 169-178, 2014.

HELOU C, JACOLOT P, NIQUET-LERIDON C, GADONNA-WIDEHEM P, TESSIER FJ: Maillard reaction products in bread: A novel semi-quantitative method for evaluating melanoidins in bread. Food Chem 190: 904-911, 2016.

HULL GLJ, WOODSIDE JV, AMES JM, CUSKELLY GJ: NE-(carboxymethyl)lysine content of foods commonly consumed in a Western style diet. Food Chemistry 131: 170-174, 2012.

JAFFE M: Über den Niederschlag welchen Pikrinsäure in normalen Harn erzeugt und uber eine neue Reaction des Kreatinins. (In German) Z Physiol Chem 10: 391-400, 1886.

KELLOW NJ, SAVIGE GS: Dietary advanced glycation end-product restriction for the attenuation of insulin resistance, oxidative stress and endothelial dysfunction: a systematic review. Eur J Clin Nutr 67: 239-248, 2013.

KOSCHINSKY T, HE CJ, MITSUHASHI T, BUCALA R, LIU C, BUENTING C, HEITMANN K, VLASSARA H: Orally absorbed reactive glycation products (glycotoxins): an environmental risk factor in diabetic nephropathy. Proc Natl Acad Sci U S A 94: 6474-6479, 1997.

LI M, ZENG M, HE Z, ZHENG Z, QIN F, TAO G, ZHANG S, CHEN J: Effects of long-term exposure to free Nepsilon-(Carboxymethyl)lysine on rats fed a high-fat diet. J Agric Food Chem 63: 10995-11001, 2015.

LUBITZ I, RICNY J, ATRAKCHI-BARANES D, SHEMESH C, KRAVITZ E, LIRAZ-ZALTSMAN S, MAKSINMATVEEV A, COOPER I, LEIBOWITZ A, URIBARRI J, SCHMEIDLER J, CAI W, KRISTOFIKOVA Z, RIPOVA D, LEROITH D, SCHNAIDER-BEERI M: High dietary advanced glycation end products are associated with poorer spatial learning and accelerated Abeta deposition in an Alzheimer mouse model. Aging Cell 15: 309-316, 2016.

LUEVANO-CONTRERAS C, CHAPMAN-NOVAKOFSKI K: Dietary advanced glycation end products and aging. Nutrients 2: 1247-1265, 2010.

MAHER P: Methylglyoxal, advanced glycation end products and autism: is there a connection? Med Hypotheses 78: 548-552, 2012.

MATTHEWS DR, HOSKER JP, RUDENSKI AS, NAYLOR BA, TREACHER DF, TURNER RC: Homeostasis model assessment: insulin resistance and beta-cell function from fasting plasma glucose and insulin concentrations in man. Diabetologia 28: 412-419, 1985.

MUNCH G, KEIS R, WESSELS A, RIEDERER P, BAHNER U, HEIDLAND A, NIWA T, LEMKE HD, SCHINZEL R: Determination of advanced glycation end products in serum by fluorescence spectroscopy and competitive ELISA. Eur J Clin Chem Clin Biochem 35: 669-677, 1997.

NOWOTNY K, JUNG T, HÖHN A, WEBER D, GRUNE T: Advanced glycation end products and oxidative stress in type 2 diabetes mellitus. Biomolecules 5: 194-222, 2015.

OTT C, JACOBS K, HAUCKE E, NAVARRETE SANTOS A, GRUNE T, SIMM A: Role of advanced glycation end products in cellular signaling. Redox Biol 2: 411-429, 2014.

PATEL R, BAKER SS, LIU W, DESAI S, ALKHOURI R, KOZIELSKI R, MASTRANDREA L, SARFRAZ A, CAI W, VLASSARA H, PATEL MS, BAKER RD, ZHU L: Effect of dietary advanced glycation end products on mouse liver. PLoS One 7: e35143, 2012. 
PERTYNSKA-MARCZEWSKA M, GLOWACKA E, SOBCZAK M, CYPRYK K, WILCZYNSKI J: Glycation endproducts, soluble receptor for advanced glycation endproducts and cytokines in diabetic and non-diabetic pregnancies. Am J Reprod Immunol 61: 175-182, 2009.

POULSEN MW, ANDERSEN JM, HEDEGAARD RV, MADSEN AN, KRATH BN, MONOSIK R, BAK MJ, NIELSEN J, HOLST B, SKIBSTED LH, LARSEN LH, DRAGSTED LO: Short-term effects of dietary advanced glycation end products in rats. Br J Nutr 115: 629-636, 2016.

POULSEN MW, BAK MJ, ANDERSEN JM, MONOSIK R, GIRAUDI-FUTIN AC, HOLST JJ, NIELSEN J, LAURITZEN L, LARSEN LH, BUGEL S, DRAGSTED LO: Effect of dietary advanced glycation end products on postprandial appetite, inflammation, and endothelial activation in healthy overweight individuals. Eur J Nutr 53: 661-672, 2014.

PRESTON AM, MASSA MUÑOZ YB, LÓPEZ LABOY L, RODRÍGUEZ MB: Glycation of blood proteins during pregnancy and lactation in the rat. $P$ R Health Sci J 11: 69-71, 1992.

RONCERO-RAMOS I, DELGADO-ANDRADE C, TESSIER FJ, NIQUET-LERIDON C, STRAUCH C, MONNIER VM, NAVARRO MP: Metabolic transit of N(epsilon)-carboxymethyl-lysine after consumption of AGEs from bread crust. Food Funct 4: 1032-1039, 2013.

RONCERO-RAMOS I, NIQUET-LERIDON C, STRAUCH C, MONNIER VM, TESSIER FJ, NAVARRO MP, DELGADO-ANDRADE C: An advanced glycation end product (AGE)-rich diet promotes Ne-carboxymethyllysine accumulation in the cardiac tissue and tendons of rats. J Agric Food Chem 62: 6001-6006, 2014.

RUHLEN RL, TAYLOR JA, MAO J, KIRKPATRICK J, WELSHONS WV, VOM SAAL FS: Choice of animal feed can alter fetal steroid levels and mask developmental effects of endocrine disrupting chemicals. $J$ Develop Origins Health Dis 2: 36-48, 2011.

ŠEBEKOVÁ K, BROUDER ŠEBEKOVÁ K: Glycated proteins in nutrition: Friend or foe? Exp Gerontol 117: 76-90, 2019.

SEBEKOVA K, KLENOVICS KS, BOOR P, CELEC P, BEHULIAK M, SCHIEBERLE P, HEIDLAND A, PALKOVITS M, SOMOZA V: Behaviour and hormonal status in healthy rats on a diet rich in Maillard reaction products with or without solvent extractable aroma compounds. Physiol Behav 105: 693-701, 2012.

SEMBA RD, GEBAUER SK, BAER DJ, SUN K, TURNER R, SILBER HA, TALEGAWKAR S, FERRUCCI L, NOVOTNY JA: Dietary intake of advanced glycation end products did not affect endothelial function and inflammation in healthy adults in a randomized controlled trial. J Nutr 144: 1037-1042, 2014.

ŠEBEKOVÁ K, FAIST V, HOFMANN T, SCHINZEL R, HEIDLAND A: Effects of a diet rich in advanced glycation end products in the rat remnant kidney model. Am J Kidney Dis 41 (Suppl 1): S48-S51, 2003.

TAN AL, FORBES JM, COOPER ME: AGE, RAGE, and ROS in diabetic nephropathy. Semin Nephrol 27: 130-143, 2007.

TESSIER FJ, NIQUET-LERIDON C, JACOLOT P, JOUQUAND C, GENIN M, SCHMIDT AM, GROSSIN N, BOULANGER E: Quantitative assessment of organ distribution of dietary protein-bound 13C-labeled Ne-carboxymethyllysine after a chronic oral exposure in mice. Mol Nutr Food Res 60: 2446-2456, 2016.

URIBARRI J, CAI W, RAMDAS M, GOODMAN S, PYZIK R, CHEN X, ZHU L, STRIKER GE, VLASSARA H: Restriction of advanced glycation end products improves insulin resistance in human type 2 diabetes: potential role of AGER1 and SIRT1. Diabetes Care 34: 1610-1616, 2011.

URIBARRI J, WOODRUFF S, GOODMAN S, CAI W, CHEN XUE, PYZIK R, YONG A, STRIKER GE, VLASSARA H: Advanced glycation end products in foods and a practical guide to their reduction in the diet. J Am Diet Assoc 110: 911-916.e12, 2010.

VLASSARA H, CAI W, CRANDALL J, GOLDBERG T, OBERSTEIN R, DARDAINE V, PEPPA M, RAYFIELD EJ: Inflammatory mediators are induced by dietary glycotoxins, a major risk factor for diabetic angiopathy. Proc Natl Acad Sci U S A 99: 15596-15601, 2002.

VLASSARA H, URIBARRI J: Advanced glycation end products (AGE) and diabetes: cause, effect, or both? Curr Diab Rep 14: 453, 2014.

WARD RE, XIAO S, MICHALSKI M-C, GELOEN A, HINTZE K: Effect of dietary carboxymethyllysine on glucose and insulin sensitivity, cecal fatty acids and the plasma metabolome in mice fed the total western diet. FASEB $J 30$ (Suppl 1): 420.4, 2016. 
WATANABE N, KAMEI S, OHKUBO A, YAMANAKA M, OHSAWA S, MAKINO K, TOKUDA K: Urinary protein as measured with a pyrogallol red-molybdate complex, manually and in a Hitachi 726 automated analyzer. Clin Chem 32: 1551-1554, 1986.

WILLIAMS MA, ENQUOBAHRIE DA, ZIMMER J, QIU CF, HEVNER K, ABETEW D, CHRISTIANSON C, SHEAFF C: Maternal plasma advanced glycation end products concentrations in response to oral 50-gram glucose load in mid-pregnancy: a pilot study. Clin Lab 58: 1045-1050, 2012.

YAN SF, RAMASAMY R, SCHMIDT AM: Mechanisms of disease: advanced glycation end-products and their receptor in inflammation and diabetes complications. Nat Rev Endocrinol 4: 285-293, 2008.

YU Y, HANSSEN KF, KALYANARAMAN V, CHIRINDEL A, JENKINS AJ, NANKERVIS AJ, TORJESEN PA, SCHOLZ H, HENRIKSEN T, LORENTZEN B, GARG SK, MENARD MK, HAMMAD SM, SCARDO JA, STANLEY JR, WU M, BASU A, ASTON CE, LYONS TJ: Reduced soluble receptor for advanced glycation end-products (sRAGE) scavenger capacity precedes pre-eclampsia in type 1 diabetes. BJOG 119: 1512-1520, 2012.

ZHANG ZY, DAI YB, WANG HN, WANG MW: Supplementation of the maternal diet during pregnancy with chocolate and fructose interacts with the high-fat diet of the young to facilitate the onset of metabolic disorders in rat offspring. Clin Exp Pharmacol Physiol 40: 652-661, 2013. 